Center for Research on

Social Organization

The Working Paper Series

The University of Michigan Ann Arbor
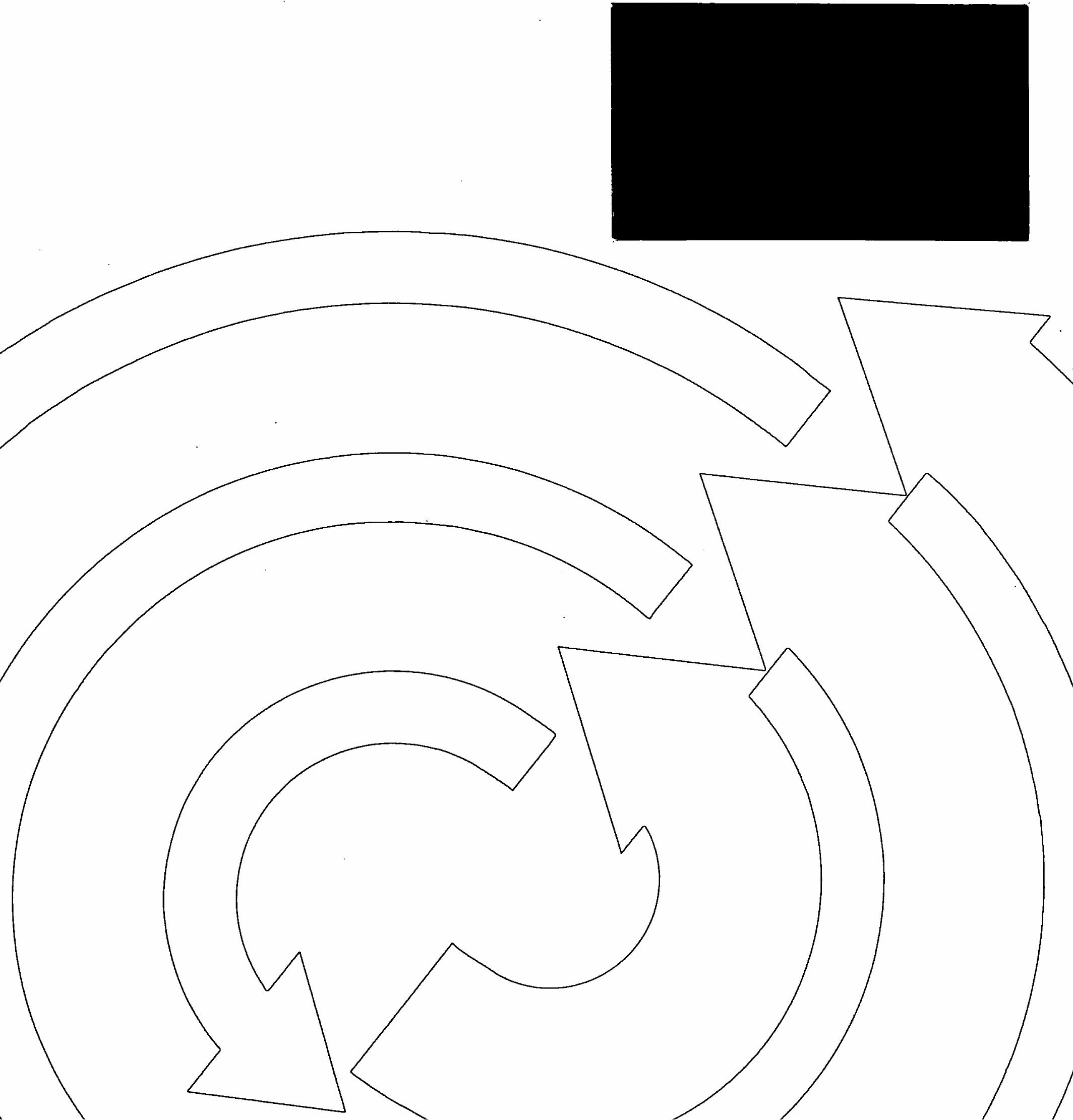
CHANGES IN MATE CHOICE IN CHENGDU by

Mart in King Whyte

\#361

September 1988 


\section{CHANGES IN MATE CHOICE IN CHENGDU}

\section{Martin King Whyte}

\section{University of Michigan}

The family is the basic unit of social organization in any society, and in Chinese culture the centrality of family organization has been explicitly acknowledged for centuries. Efforts to change society must deal with the family as an institution, and since the process of mate choice is a central defining element of family organization, changes in the nature of the mate choice process will be an important aspect of such change efforts. In this paper I wish to consider how the nature of the mate choice process has changed over time in urban China. I am concerned here with both long term and short term changes. In the long term I want to examine how much the process of mate choice has changed in general since 1949 in the PRC. From a short term perspective I am interested in how much this process has been changed in the post-Mao or reform period.

In discussing changes in the process of mate choice in urban China I will rely primarily on data from a survey of mate choice and marriage relations in Chengdu on which I have been collaborating over the last several years. My collaborators in this research are Yuan Yayu and $\mathrm{Xu}$ Xiaohe, from the Sociology Research Office of Sichuan University, although they bear no responsibility for the particular interpretations offered here. The Chengdu survey was conceived as a partial replication of a survey on mate choice and marriage relations I directed in the Detroit metropolitan area in 1984 , and so in some places I will compare results from the Chengdu survey with figures drawn from the Detroit study, in order to compare and contrast mate choice in urban America and urban China. ${ }^{1}$ The survey data from Chengdu were collected from a representative

\footnotetext{
1. Of course, neither city is "typical" of all urban areas in either society, and in terms of population ranking, industrial structure and other criteria the two cities are not the ideal comparisons. I believe that the broad lines of the findings from these cities are not atypical of other urban areas in these two societies, but in the absence of comparable data from such areas (not available in either
society). I cannot address the issue of typicality directly.
} 
sample of 586 ever-married women between the ages of 20 and 70 in the two main urban districts of Chengdu in May of 1987 , and the response rate was $87.7 \% .^{2}$ The interviews were conducted by sociology students from Sichuan University via face-to-face interviews, usually in the homes of the respondents, but in some cases in the workplace or some other location. The Chengdu respondents had first married over a range in years from 1933 to 1987 , and so it is possible to make both longer term and shorter term comparisons of the nature of the mate choice process with these data.

\section{The Background on Changing Chinese Mate Choice}

The process of mate choice has been an arena of contention for Chinese reformers and revolutionaries for much of the twentieth century. The main features of the "traditional" system of mate choice in China are fairly familiar. Most marriages were arranged, and in many cases what was involved was a fairly extreme form that could be termed "blind marriage," in which the bride and groom did not even meet until the day of the wedding. Not only was consent of the principals not required, but ages and relative ages could be suited to family concerns rather than individual preferences, resulting in such phenomena as "adopted little daughters-in-law," child betrothals, and large age disparities between spouses in either direction. Partly in order to insure parental control over the mate choice process, there was substantial effort to control the social interactions of young people and particularly of daughters, with the preservation of female virginity being of particular concern. There was no direct governmental regulation of the act of marriage, in terms of licenses, registration, or laws effectively restricting ages at marriage, and the wedding feast (usually held by the groom's family) and associated ritual activities were what determined that the couple was considered married. Marriage finance negotiations were usually part of the mate choice process, and these commonly involved both a bride price and a dowry component, with the importance of these components varying by class, region, and other factors.

2. The Detroit sample was only slightly different. In all a representative sample of 459 ever-married women between the ages of 18 and 75 were interviewed in the tri-county metropolitan area (Wayne, Oakland, and Macomb counties), and the response rate was $74 \%$. 
But commonly the bride's family made demands on the groom's family for various gifts in cash and kind to be delivered to them, and they in turn expended some of these and perhaps some of their own resources in equipping the bride with a dowry which was transported with her into her marriage. As the preceding phrase indicates, most often the new bride went to live with her groom's family after the wedding.

These "traditional" marriage customs were already under attack from the early decades of the twentieth century, and they were beginning to change gradually. ${ }^{3}$ The most spirited attacks of the May Fourth reformers focused on the system of arranged marriage, but other elements, such as lavish wedding feasts, patrilocal post-marital residence, and even the stress on female virginity, received some criticism as well. To some extent industrialization and increasing wage labor fostered changed mate choice customs, but probably the main impetus for change was Westernization. Through increasing exposure to Western ideals of freedom of mate choice, romantic love, and neolocal postmarital residence, some portion of the Chinese populace came to see changed marriage customs as a requirement of modernity. Still, even on the eve of the Communist victory in 1949 , changes in the direction of such Western-style mate choice customs were mainly confined to a portion of the well-educated urban elite, and had not had that much impact on less educated urbanites or rural residents. ${ }^{4}$

The story of changes in Chinese family life after 1949 is also fairly familiar and will not be reviewed here in detail. ${ }^{5}$ For the purposes of the analysis that will be presented here, I wish to consider the underlying mechanisms that may have fostered changes in marriage customs in different periods, and what impacts they might be expected to have. I will argue that there are three distinctive change mechanisms that have been operating, separately or in combination, in

3. No detailed discussion of these earlier changes will be offered here, given the ample writings on this topic by others. The best known works in English are Olga Lang. Chinese Family and Society, New Haven: Yale University Press, 1946; and Marion Levy, The Family Revolution in Modern China, Cambridge: Harvard University Press, 1949.

4. A good general overview of changes in the Chinese family, both before 1949 and through the 1950 , is presented in William Goode, World Revolution and Family Patterns. New York: The Free Press, 1963, Chapter 6.

5. Among other works, there are detailed treatments in the two works the current writer co-authored with William Parish, Village and Family in Contemporary China and Urban Life in Contemporary China (both University of Chicago Press, 1978 and 1984 , respectively). 
various periods since 1949: governmental direct change efforts, social structural changes, and cultural influences produced by Western impact.

The most familiar change mechanism is direct governmental change efforts. ${ }^{6}$ What is involved is direct efforts by the party/state in the PRC to use laws, regulations, propaganda, campaigns and other mechanisms to get people to alter their marriage customs. The authorities perceive that they are trying to induce the population to refrain from following old "feudal" or "bourgeois" marriage customs and to begin following "socialist" practices instead. The desired socialist marriage practices would include freedom of mate choice, marriage only in adulthood (and, increasingly, "late" marriage), the absence of marriage finance demands, mate selection based upon compatibility and political/moral criteria rather than such factors as wealth or attractiveness, and simple and frugal wedding celebrations without elaborate feasts or traditional ritual activities. ${ }^{7}$ Some traditional marriage customs, however, were not on the "must change" list. For example, virginity was stressed by the new order if anything more than the old, although now perhaps it was intended to imply to males as well as females. And patrilocal post-marital residence was never the object of concerted criticism. ${ }^{8}$

If direct family change efforts have been the major force for changes in marriage customs, what pattern of change over time might we expect to find? Although there have been some alterations in the specifics of family policy in the PRC over time, particularly the changing stipulations on minimum marriage ages, ${ }^{9}$ the most important changes have involved not policies,

6. Indeed, many works on family change in the PRC largely restrict their attention to such direct change efforts. See, for example, C. K. Yang. The Chinese Family in the Communist Revolution, Cambridge: MIT Press, 1959; and M. J. Meijer, Marriage Law and Policy in the Chinese People's Republic, Hong Kong: Hong Kong University Press, 1971.

7. In some periods there were attempts to replace ritual practices such as the couple bowing to ancestral tablets and the new bride serving tea to and/or washing the feet of her mother-in-law, which conveyed filiality and familial subordination, with new ritual elements, such as bowing to a portrait of Mao and pledging loyalty to the CCP, which express subordination instead to the new political system.

8. Occasionally articles have appeared in the press pointing to the advantages of matrilocal post-morital residence, and these became more common in the 1970 s when it was increasingly recognized that the patrilocal custom posed obstacles to the regime's family planning goals. And the 1980 revised marriage law does, unlike the original 1950 marriage law, state that the couple can live after marriage with either the bride's family or the groom's family. (See article 8 of the 1980 law, translated in Pacific Affairs, Vol. 57:266(1984). Interestingly, the new law makes no mention of the possibility of the couple living neolocally, even though we will see that this is the most conmon option in urban Chengdu and, no doubt, in other cities.) Still, in none of the major direct change efforts aimed at the family since 1949 has post-marital residence been an important focus.

9. The 1950 marriage law stated minimum marriage ages of 18 for females and 20 for males. By the 1970 s administrative pressure was being used to foster late marriage, and in urban areas this often meant efforts to enforce a minimum marriage age of 25 for 
but priorities. As in other realms, there have been "high tides" of family change efforts-particularly in $1950-53,1958-60$, and in the Cultural Revolution decade (1966-76). The latter period can be regarded as a time of the most pervasive and sustained hostility to "non-socialist" marriage customs. Since Mao's death and in the period of the post-Mao reforms, in contrast, there has been a considerable relaxation of official efforts to foster family change. If directed change efforts are the primary mechanism of altering marriage customs, then, we might expect to find movement away from "socialist" mate choice and weddings in the reform era. Whether this movement would take the form of revivals of traditional marriage customs or increased salience of Western "bourgeois" practices would depend upon other factors.

The second major mechanism I wish to consider is social structural changes. As has been argued in detail in my earlier work with William Parish on rural and urban social trends, the underlying argument behind this mechanism is that people tend to respond not to government policies and propaganda, but to the changing social structure in which they live. If that social structure changes, whether through economic development, direct governmental change efforts, or other forces, then people will adapt their behavior to the new structure around them.

The most extensive discussion of how industrialization, urbanization, and other forms of modernization of social structure foster changes in marriage customs is provided by William Goode. ${ }^{10}$ At the center of his argument is the idea that modernization fosters a change from families as production units to families as consumption units, with a rise of wage labor outside of the home. In so doing family transmission of occupational skills and of property becomes less important in achieving adulthood, and competition via schooling and in an increasingly non-family based job market become more and more important. As a result, young people are less dependent upon familial resources for achieving adulthood and have more opportunities to meet and get to know potential mates, and families have less motivation to try to maintain strict control over such

females and 27-8 for males. The 1980 revised marriage law set new legal minimum marriage ages at 20 for females and 22 for males, and by so doing to some extent undermined the effort to foster late marriage by administrative measures.

10. See World Revolution and Family Patterns. op. cit. 
matters as mate choice and post-marital residence. So modernization can be expected to produce a number of changes in marriage customs. But other structural changes in society besides those associated with gradual economic development can be expected to influence family practices as well. In particular, it can be argued that inducing socialist transformation in many ways accelerates changes that would occur over decades as a result of economic development, because through socialist transformation the elimination of family property transmission and the thrusting of young people into non-familial wage labor force competition occur all at once.

While the detailed consequences for marriage customs under this mechanism can only be inferred by a systematic analysis of the structural elements of the changed social order, in general it may be suggested that the effect of modernization-related structural changes and of socialist direct governmental change efforts on marriage customs will in many ways coincide, but in some instances will differ. In particular, both mechanisms can be expected to foster increasing freedom of mate choice, rising ages at marriage, and a declining importance of marriage finance negotiations. ${ }^{11}$ However, one would expect increasing neolocal post-marital residence to occur as a result of modernization although this is not stressed in official direct change efforts, and one would not expect modernization to foster wedding simplification or the maintenance of a norm of premarital chastity.

If the structural changes in Chinese society are the main impetus for alterations in marriage customs, the pattern of actual changes over time should be different from that described for governmental direct change efforts. We should expect to find a major difference between marriages that occurred before 1949 or even before 1955 and those that began afterward. However, we would not expect to find further clear changes induced by the Great Leap Forward or the Cultural Revolution, since these did not, for all of their sound and fury, produce major

11. In an earlier article I compared the predictions drawn from Goode's theory of modernization-induced family change and family policy in the PRC. See "The Family" in M. Oksenberg, ed., China's Developmental Experience, New York: Praeger, 1973. In general Goode's theory is one of "convergence," with family forms in socialist and capitalist societies becoming more and more similar as they become modernized economically. It should be noted, however, that changes in social structure produced by socialist transformation may in some cases work contrary to the government's direct family change efforts, as in the shift to more of a pure bride price system of marriage finance in rural Guangdong after collectivization. 
changes in the way urban society was structured. ${ }^{12}$ What we should expect to find for the reform era is less clear. On the one hand you have fairly rapid economic development, higher levels of schooling, and rising living standards in urban areas, which might be expected to produce further incremental movement toward more "modern" marriage customs, although the basic structures of urban life have not yet changed very much. On the other hand the reforms have entailed a modest amount of reduced bureaucratic control over all urban resources and on a small scale the same rise of family-run enterprises that is occurring on a much more widespread basis in the countryside. Insofar as there is an increasing salience of family-controlled resources, we might expect to find a revival of some traditional aspects of marriage customs in the reform era, rather than a strengthening of "modern" forms.

Our third and final change mechanism is Westernization. The assumption underlying this mechanism is that as ideas and cultural influences flow into China from the outside world, and particularly from the West, those exposed to such influences will be likely to change their family behavior in order to copy Western forms. As a consequence, Western customs of mate choice, ideas about love, ways of celebrating marriage, and other practices will become defined as "advanced" and "modern," and some Chinese will attempt to gain prestige by following imported customs and practices. In terms of the expected direction of family change, this mechanism leads to the same sort of predictions as our modernization-related structural change mechanism, since it is the results of more advanced modernization in Western countries that will be copied. But the nature of the change process has more in common with our first mechanism, direct governmental change efforts, since it is assumed that exposure to influential ideas and cultural practices can induce changes in marriage behavior, even if the social structure in which one lives has not been substantially altered. If we think in terms of Marxist categories, we might say that both directed

12. The Great Leap did, for a short time, produce dramatic structural changes in rural society in the early people's communes. However, with the collapse of the Leap and the revision of commune organization, what emerged by 1961-2 was a structural form that was in most respects a direct carry-over from the APCs of 1956-8. Urban areas experienced no comparable structural transformations after the mid-1950s. 
change efforts and Westernization imply an "idealistic" approach to change while social structureinduced changes imply a "materialistic" set of assumptions. ${ }^{13}$

If Westernization has been the major mechanism of change in marriage customs, the pattern of changes over time we would expect to find is fairly clear. Western influence was prevalent in urban areas of China prior to 1949 (although more so in major coastal cities than in interior cities such as Chengdu). After 1949, however, factors such as the takeover effort, the Korean War, and the American blockade combined to produce a sharp reduction in Western influence in China and a major propaganda campaign against the glorification of Western ideas and customs. ${ }^{14}$ From the 1950 s into the 1970 s Western ideas and influences were kept to a minimum in China, but in the post-Mao era this situation has changed dramatically. Sharp increases in Westerners in China; Chinese travelling and studying in the West; and access to Western movies, television serials, fashions, and other cultural products have produced renewed exposure to, and admiration of, Western culture and society. In addition, there is increasing awareness in China of the patterns of sociai life in more substantially Westernized Chinese environments in Hong Kong, Singapore, and Taiwan. This awareness may help make Western ways seem less "alien" than in the past, and more suited to Chinese conditions. In any case, the products of Western influence are widely visible in urban China today, whether they involve youth interest in rock music and disco dancing, a revival of Christianity, television viewing of "Little House on the Prairie" and "My Favorite Martian," or China's top leaders wearing Western business suits. We might expect, then, to find marriage customs also increasingly subject to Western influence in the reform era.

13. However, the social structural change mechanism is broader than Marxist materialism in assuming that a variety of changes in social structure, and not only those involving economic forces and class relations, can cause changes to occur.

14. Of course, in the 1950 s Western influence was partially replaced by Soviet influence, and I will not get into the debate here about how "Western" the Soviet Union is. Still, on balance Western influence in China was dramatically reduced, and by the 1960 s even Soviet influence had been substantially curtailed. See the discussion in Beverley Hooper, China Stands Up, London: Allen \& Unwin, 1986. 
In the pages that follow I will utilize information from our urban survey in Chengdu to view changes in marriage customs since the years prior to 1949 , and to try to see whether the patterns I find provide evidence for one or another of the underlying change mechanisms I have just discussed. Given the nature of these data and the somewhat overlapping quality of earlier predictions from various mechanisms, it cannot be expected that I will be able to finally conclude that all changes observed fit consistently into the expectations provided by one particular change mechanism. Still, it may be of considerable interest to see in some detail, and from a high quality sample survey, what the actual pattern of changes in marriage customs has been.

Each of the following tables presents simple two-way tabulations from a large number of different measures included in the Chengdu questionnaire. Since the figures follow a common format, it is important to explain how they are being presented. The marriage customs of our respondents are compared, not in terms of their age or year of birth, but in terms of the year in which they first got married. ${ }^{15}$ And I present here results with respondents divided into five "marriage cohorts." The divisions in each case are not based upon standard decade or half-decade periods, but correspond roughly to the major political shifts that are commonly used to periodize contemporary Chinese history. The first marriage cohort consists of all of those respondents who were first married prior to $1949 ; ;^{16}$ the second includes those married after 1949 but prior to the Great Leap Forward; the third consists of those who married after the onset of the Leap but prior to the Cultural Revolution; the fourth is composed of those who married during the Cultural Revolution decade; and the final marriage cohort contains all of those women in the sample who first married in the post-Mao era. Where appropriate the tables also include comparable figures from the Detroit survey, and in that case I present only overall figures, ignoring for the most part

\footnotetext{
15. Ninety-four percent of the Chengdu respondents had been married only once, so, although we collected some information on customs involved in remarriages, only first marriages will be considered here. In contrast, in the Detroit survey $84 \%$ of the respondents had been married only once.

16. Technically, since Chengdu did not fall under Chinese Communist control until the end of 1949, perhaps I should have made the dividing year 1950. However, shifting a single year (in this case, 1949) between categories does not substantially alter the results reported here.
} 
changes over time. In the text that follows I will not attempt to provide an interpretation of every nuance of each measure. Instead, I will be primarily concerned with the overall pattern of changes over time, and in particular with whether the comparison of the experiences of those who first married in the reform era (in column 5) and the rest of the sample fits one or another of the change mechanisms discussed above.

\section{Table 1 about here}

In Table 1 I present results for several different questions aimed at assessing the degree to which a marriage was arranged by parents or not and also questions about other aspects of the mate choice process that may be considered related to freedom of mate choice. Several observations can be made about these results. First, and not surprisingly, it is apparent that a major shift away from the traditional pattern of parentally arranged marriage has occurred, with the instances in which parents dominate the proceedings declining from $60-70 \%$ of the pre- 1949 marriages to under $10 \%$ today. Relatedly, those who met their husbands directly rather than through an introduction, those whose introductions came from peers rather than parents, those who had some romantic relationship and even dates prior to marriage, and those who describe themselves as having been in love, have all increased sharply in comparison with the pre-1949 era. ${ }^{17}$

17. It must be acknowledged, however, that respondent and other biases may exaggerate the changes. For example, it may be politically acceptoble to say that your parents arranged your marriage if you married before 1949 but not if you married more recently. Even though precautions were taken to assure respondents that this was an academic study, that their answers would be strictly confidential, and that their participation was voluntary, still in the context of recent Chinese history, in which survey research is new and unfamiliar and the political risks of unacceptable expression old and familiar, we cannot be certain how frankly our respondents answered questions such as these. See the general discussion of these and other problems in Stanley Rosen and David Chu. Survey Research in the People's Republic of China, Washington: United States Information Agency, 1987. Still, since I am primarily interested here not in the pre-1949/post-1949 comparison, but in the contrast across periods in the PRC and particularly between pre-reform and post-reform eras, this sort of bias should not affect my conclusions on those later periods. This is the case because, even if respondents are overstating somewhat the degree of freedom and romance in post-1949 marriages, and understating the degree of parental control, there is no reason to expect that respondents who married in one of the latter four periods should exaggerate more than those in other periods. One other factor that may produce an exaggerated impression of change over time in these results is the fact that our sample is composed of women currently resident in Chengdu, but not necessarily resident in that city when they married. Thus the earliest marriage cohorts have more members who grew up outside of Chengdu, and often in rural areas, where their marriage customs would not be expected to reflect urban marriage customs at that time. (The percentage of women who were married in Chengdu is $56 \%, 50 \%, 74 \%, 72 \%$, and $91 \%$ in the five marriage cohorts.) Preliminary examination of comparable tables with only those who married in Chengdu included indicated that only for the second marriage cohort is the "traditionalism" of marriage customs somewhat exaggerated by the presence of women who married in rural areas. The results for the first cohort do not change inuch if I consider only urban marriages prior to 1949 , which indicates that urban and rural customs were not as different before 1949 as they were to become afterward. 
These results also make it clear that compared with the American situation, there remain. important restraints on individual choice of a mate even in recent years, a conclusion that is hardly surprising. We did not ask our Detroit respondents whether their marriages had been arranged, but from Table 1 it is apparent that more of them met their husbands directly than did our Chengdu respondents, and that even when introductions occurred they were more likely to come from age peers. Parental influence is more clearly visible in the Chengdu sample. We can also detect evidence in these results that no real "dating culture" has yet emerged in Chengdu. ${ }^{18}$ Although it is not evident from these figures, for most young people still today dating primarily takes place after the selection of a potential spouse, rather than prior to that decision, and even then in recent times $30-50 \%$ of our respondents say they rarely or never had dates with their eventual husbands (see \#6). There has been a modest increase in the number of women who say they had other romances prior to marriage, but such women still represent less than $30 \%$ of all respondents, in contrast to the two-thirds of Detroit respondents who had had other boyfriends (see \#7). And there has been very little increase in the proportion of women who had other men they considered marrying before they married their first husbands, with this being the case for less than $10 \%$ of Chengdu respondents, in contrast to almost half of the Detroit women (see \#8). In general, then, even though young people have more say in mate choice than their parents do in contemporary Chengdu, they must make a selection of a mate without much prior romantic experience, and once they have made a selection it is very difficult to change their minds and try a different partner. In this sort of context I was somewhat surprised to see how many respondents in recent cohorts said that they were completely (quanxin) in love with their eventual husband and had no doubts prior to the wedding (see \#9 and \#10). It would appear that either the power of positive thinking or post-hoc dissonance reduction makes Chinese respondents able to interpret

18. The defining elements of a dating culture have been disputed, but central traits would include the ability of young people to link up romantically without adult supervision in a setting that is not defined as leading to marriage. In such a setting a marketplace analogy is accepted, in which it is normatively accepted that one can "try out" various romantic partners before finally settling on one of them for marriage. See the discussion in John Modell, "Dating Becomes the Way of American Youth," in L. Moch and G. Stark, eds., Essays on the Family and Historical Change, College Station: Texas A\&M University Press, 1983. 
their mate selection as more unproblematic than American respondents, even though the latter have had more chances to consider alternatives. ${ }^{19}$

The third major conclusion to emerge from these data, and the one most relevant to the present discussion, is that the pattern of change over time in aspects of freedom of mate choice seems to fit what I would expect from the social structural change argument, and not what I would expect either from direct governmental change efforts or Westernization as change mechanisms. This conclusion is based upon the fact that the apparent changes in freedom of mate choice seem to have been well established by the end of the 1950 s. There are only modest signs of changes since then, either in the Cultural Revolution era or in the reform era (compare columns 3 , 4, and 5). In only one instance, involving frequency of dating with the eventual husband (\#6), do I find much evidence of further change in the years after 1958, with more recent brides reporting that they had dated their fianc's often. (Questions \#7-10 show some small signs of change after the 1950s, but not much further change during the reform era.) So with one minor exception, what we see in Table 1 appears to be evidence of initial change followed by substantial stability, with a predominantly youth-initiated but still relatively constrained (by American standards at least) mate choice system persisting through various changes in leadership and political lines. In the reform era there are no clear signs here of either a revival of traditional family controls or of further changes induced by Western influence, unless frequency of dating the eventual husband can be counted as the latter. But the major battle for freedom of mate choice seems to have been won by the end of the $1950 \mathrm{~s}$, as a result of the major changes in the structure of urban social life that had occurred, and no comparable shifts have taken place since that time.

Could the crudeness of the division into five marriage cohorts obscure important fluctuations in the freedom of mate choice over time? In order to investigate this question I constructed a

\footnotetext{
19. Of course, it might be argued that it is precisely the existence of alternatives in America which promotes doubts about the final choice. The Detroit figures on recollected love feelings are not strictly comparable to the Chengdu figures because in the DAS survey we utilized a seven-point scale, starting at "head over heels in love." My collaborators in Sichuan felt that Chinese respondents would have trouble making distinctions along a 7-point scale, so they orgued for the 5-point scale we eventually used.
} 
summary scale from six of the freedom of choice measures included in Table $1 .{ }^{20}$. I then computed a three year moving average of the resulting summary freedom of mate choice scale scores and graphed this against the year in which respondents got married. ${ }^{21}$ The result is Figure 1.

Figure 1 about here

Several things are apparent from examining Figure 1. First, the graph confirms my final and most important conclusion above: there has been little change in the overall degree of freedom of mate choice within the sample since about 1957. Neither the Great Leap Forward, the Cultural Revolution, nor the reform era has produced clear trends toward a further increase (or for that matter a reduction) in the trend away from arranged marriages. However, another trend is revealed in the graph that was obscured when I lumped together all pre-1949 marriages in Table 1, as well as all marriages in the years 1949-57. The increase in overall freedom of mate choice during the 1950 s, during the midst of major social structural changes, is dramatically shown. But the graph also reveals that there was a shift in the direction of more freedom of mate choice already underway in the pre-World War II period, so that women who married during the 1940s were enjoying somewhat more freedom in picking a mate than their elder sisters, aunts, and mothers had earlier. This finding should not be entirely surprising, since it confirms the "family revolution" that Marion Levy, Olga Lang, and others argued was underway prior to 1949. Given my primary interest here in post-1949 social trends, I won't enter into the debate here about what the sources of these earlier changes were. Suffice it to say that both social structural changes (such as increases in female education and non-family wage labor) and Western cultural

20. The items included were $\$ 1,2,3,6,7$, and 9 , all scaled so that a high value indicated more freedom of choice. The items were chosen based upon the strength of their mutual intercorrelations, and the average among all six items was $r=.42$. The scale was computed based upon the mean of the standardized (or $\mathrm{Z}$ ) scores on each item

21. A three year moving average calculates the mean of one year and the years before and after it-for example, the value for 1957 would be an average of the means computed for 1956,1957, and 1958. The reason for using this moving average procedure is to smooth out the fluctuations that would occur from year to year, especially in the early years represented in the graph, where the number of respondents used to compute these averages is fairly small. As a result of this sort of smoothing process, the primary trends in the data can be more readily seen. 
influences (transmitted by May Fourth era reformers) were involved, with governmental directed change efforts not an important factor.

\section{Table 2 about here}

In Table 2 I display a more miscellaneous set of responses from the Chengdu survey, all of which have something to do with the circumstances that existed at the time our respondents first married. Items \#1 and \#2 show patterns similar to what we have seen in Table 1 . Both in actual patterns of work prior to marriage and in expectations of working after marriage, a dramatic shift occurred which had been consolidated by the end of the 1950 s, so that the great majority of women worked prior to marriage, and with few exceptions they expected to keep working throughout their married lives. There is a modest further increase in the percentage of women who worked before marriage in recent cohorts, but this increase may be due simply to the fact that the marriage age has continued to climb in the sample (see \#11), rather than resulting from any alternation in customs and expectations. Other items in the table that follow a similar pattern of change consolidated by the end of the 1950 s are \#6, which shows a "regularization" of marriage, with fewer cases involving husbands who had been married before, and \#10, which shows an increase in the time couples were acquainted prior to marriage.

One other item, \#7, bears some resemblance to this pattern, but with some differences. In this case what we have is an indirect effort to examine the extent of premarital sexual experience. In one portion of the questionnaire we ask women how old they were when they first had various experiences, including their first sexual experience, and from other parts of the questionnaire we can determine their age when they first married. Simple subtraction allows me to construct a conservative estimate of the proportion of respondents who had sex prior to marriage. (Conservative because those who had sex prior to marriage but then married before their next birthday would not be distinguished from women who remained virgins until marriage.) $)^{22}$ In this

22. The figures given may also be a conservative estimate because some women may have lied about when they had their first sexual experience. There was a disturbing tendency for some respondents to report ages of first sexual experiences that were latersometimes substantially later-than the ages at which they got married. Although part of this tendency-which was not visible in 
instance we see an apparent jump in premarital sexual experience occurring for women who married in the early 1950 s, and then rough stability, although with premarital sex perhaps becoming slightly more likely among recent cohorts. ${ }^{23}$

The second and higher estimate of premarital sexual experience shown in the table (in row \#7a) makes use of other information--on whether the respondent is estimated to have conceived her first child prior to marriage (see rows $\# 8 \mathrm{a}$ and $8 \mathrm{~b}$ ) or whether she cohabited prior to marriage (see row \#9). Respondents who according to one or more of these three measures had premarital sexual experience are counted in row \#7a. And the figures in that row show both higher estimated levels of premarital sexual experience overall, and a modest further increase in such experience in the reform era. Whichever set of estimates is relied upon, these data provide evidence, if such is needed, that premarital sex remains much less common in urban Chengdu than in urban Detroit. In fact, among the youngest cohorts of Detroit women we interviewed the percentage of non-virgins at marriage as detected by the method used for computing row \#7 rises to over $80 \%$, whereas even using all information available to me the estimated proportion of recently marrying females in Chengdu who were not virgins at marriage was only $30 \%$.

Two other contrasting patterns are visible for other items in Table 2. The items about parental approval of the groom (\#4 and \#5) show general stability over time (although there is some decrease in the percentage of parents strongly approving between the first and second marriage cohorts). Evidently, whether the parents did the choosing or whether the young people themselves took the initiative does not have too much effect on the level of approval that the parents give to the match. This pattern could be taken to indicate that even when young urban Chinese make their own choice of a mate they heavily take the preferences of their parents into

the data from Detroit respondents-may be attributable to traditional Chinese age reckoning practices, which yield ages one or two years above the actual age. I suspect that overzealous efforts to conceal premaritai experiences may also play a role. Loss of virginity prior to marriage is still a matter of considerable shame and personal risk in China. As noted earlier, though, any bias of this type should be roughly constant across marriage cohorts. This means that I should be able to see trends in such data, even if the precise levels are underestimates.

23. Of course, in most instances premarital sex probably occurred with the eventual husband, and so these percentages represent something considerably less than "free love." Also, the fact that marriage was occurring later and later, as shown in \#11, needs to be taken into account in interpreting this trend. 
consideration. However, even in Detroit, with a much higher level of youth autonomy in dating and mate choice, the levels of parental disapproval are only modestly higher (see column 6). My measure of premarital births and conceptions (\#8) also shows only a slight change across time periods. $^{24}$

The figures for ages at marriage shown in \#11 and \#12, in contrast, show a pattern of linear increase, with average marriage ages continuing to climb (and more steeply for women than for men) across all cohorts. However, I suspected that, as with freedom of mate choice, the crude time categories used in Table 2 might obscure important trends. For that reason I computed the average female age at marriage for each year of marriage, and then I graphed the three year moving average of female marriage ages that I had calculated. The results are shown in Figure 2.

\section{Figure 2 about here}

Several interesting features are visible from this graph. First, as in Figure 1, changes were already underway prior to 1949 . Roughly speaking, the average female age at marriage had already increased from about 17 to around 19 prior to $1949 . .^{25}$ Second, throughout most of the years since 1949, a dominant tendency toward gradually increasing ages at marriage is visible. This pattern does not fit what we expect from the directed change mechanism, since forceful advocacy of late marriage did not begin until at least the 1960s, if not the 1970s. Nor does Western influence provide a "fit" with this long term trend. The structural changes associated with the takeover and socialist transformation in the 1950 s also do not fit, unlike what we saw in

24. The timing of first birth measure again is an indirect one, based upon comparing dates of marriage and dates of first birth, and of course this technique is subject to some errors. Even if this method of estimation were very accurate, it would still yield a conservative picture of the extent of, and trends in, premarital sex. This is the case not only because women who are sexually active prior to marriage may not become pregnant, but also because even if they do they may be able to arrange to get an abortion. One study in a Tianjin hospital reported that the percentage of abortions there involving unmarried women rose from 9\% in 1977 to $16 \%$ in 1979. See Kathrine Lyle, "Planned Birth in Tianjin," The China Quarterly, no. 83, 1980, p. 560. And a press report claimed that in $198627.9 \%$ of all of the abortions performed in Peking involved unmarried women. (See Emily Honig and Gail Hershatter. Personal Voices, Stanford: Stanford University Press, 1988, p. 114.) If more and more premarital pregnancies are ending in abortions, then figures based upon the date of birth of the first child will not reveal the full measure of any trend toward increases in premarital conceptions.

25. The even lower figures shown for the years prior to 1935 are something of a fluke produced by a snall number of unusually young marriages in the sample and are not a realistic estimate of general marriage ages at that time. 
the case of freedom of mate choice earlier. However, it seems likely that other, more gradually evolving structural changes hold the clue to this dominant trend. To be specific, increasing schooling for women, growing employment and income earning opportunities (see row \#1), and a tightening housing supply situation provided sources of gradual change that might explain the pattern visible in Figure 2.

In addition to this primary trend toward later ages at marriage, Figure 1 also reveals several interesting reversals. There are temporary "peaks" in female marriage age in 1959, 1966, and 1979, and these are followed by reductions in the following years. These secondary trends are more readily intepretable in terms of the directed change mechanism than the other explanations. The first "relapse" occurred in the wake of the Great Leap Forward and its ensuing famine, when concern about feeding the population superceded any efforts to enforce family change goals. The second instance corresponds to the latter stages of the Cultural Revolution, a time during which political chaos made concerted governmental pressure for late marriage impossible. The third reduction in average female marriage ages is the most striking. According to these figures, the average female marriage age has declined by about three years (from about 26 to roughly 23 ) in the years since 1979. As noted earlier, it was at the start of this period that the new marriage law, with its de facto reduction of minimum marriage ages, was promulgated. It is hard to avoid the conclusion that the 1980 law, by reducing directed change efforts to enforce even later marriage ages, was a primary contributor to this striking drop. ${ }^{26}$ However, other factors may have contributed as well. The policy of sending massive numbers of urban youth to the countryside may have contributed to the pre-1979 increase by leading many to postpone marriage until they could return to the cities, when they had to initiate the mate selection process relatively late. The discontinuation of this program at the end of the 1970 s eliminated one important source of delays in marriage. In addition, perhaps the modest increases in dating and

26. Even though the 1950 marriage law had proclaimed 18 as the minimum marriage age for females, since the early 1970 s urban authorities had been trying to enforce a much higher minimum, usually around 25 . Thus the effect of the 1980 law was to provide some legal grounds for females marrying as young as 20 . It should be noted that data from a national fertility survey reveal trends in urban marriage ages that are very similar to those shown in Figure 2--both in terms of the primary trend and in regard to the secondary dips in marriage ages. See Judith Banister, China's Changing Population, Stanford: Stanford University Press, 1987, pp. 156-7. 
premarital intimacy discussed earlier have helped to encourage somewhat earlier marriage, as has rising prosperity. ${ }^{27}$ In any case, the primary trend visible for marriage age to increase seems readily interpretable in terms of the sorts of structural factors focused on by theorists of the modernization process, while the secondary trend toward reduced ages in some periods can be explained through a combination of directed change efforts and structural change influences.

Only a few other items in Table 2 yield signs of a changing pattern of mate choice in the reform era, and those signs are rather slight. In addition to the rise in the proportion of brides already at work shown in \#1, there is another aspect of the "regularization" of family life shown in the increased percentage of brides whose parents were still together when they married (in \#3). In the Chinese context the primary causes of family disruption are death and family separation, rather than divorce, which is the primary cause in the Detroit sample. Impressive increases in life expectancy in the PRC make it increasingly likely in recent years that women will be able to marry from "intact families."

In \#9 there is also some evidence of a rise in premarital cohabitation, a trend for which I have no full explanation. ${ }^{28}$ Increases in premarital cohabitation have begun to be reported in the Chinese press as well, but the circumstances are not fully described. Harsh enforcement of late marriage is said to be one factor leading couples to cohabit prior to the wedding, but with a relaxation of such pressure the urge to live together prior to marriage should be reduced. Some accounts suggest that anxieties about the marriage market and parental cooperation in providing housing space are factors fostering premarital cohabitation, but it is not clear to me how cohabiters avoid getting into trouble with the grass roots moral "enforcers" who are so ubiquitous

27. I considered one other possible explanation. In rural areas there has been a substantial reduction in secondary school enrollments in the reform era, a reduction that perhaps affects the educational attainment of rural women most of all. Other things being equal, reduced years of schooling should promote earlier marriage. However, l discovered that women in the sample who married in the mid-1980s tended to have had slightly more years of schooling than women who married at the end of the Mao era. (Interestingly, this examination also revealed that even in recent years women have not regained the high educational attainment levels they had achieved just prior to the onset of the Cultural Revolution, when at marriage the average woman had an upper middle school education or slightly more.)

28. The cohabitation question was a direct one, unlike the questions on premarital sex and pregnancy, and one that I had thought was eliminated as unsuitable to Chinese conditions and was surprised to see included in the final questionnaire. It might be noted that the Detroit figure on cohabitation conceals a striking recent increase, with $40 \%$ of the women who married within the final five years covered by the survey saying they had lived together prior to marriage. 
in Chinese neighborhoods and work units. Press critiques of this emergent trend place the blame squarely on the influence of "decadent" Western ideas, but it is not clear that we should take this explanation seriously. ${ }^{29}$ In any case, there appears to be the modest beginnings of a trend toward premarital cohabitation in the reform era, even if the sources of this trend remain somewhat obscure. To summarize, while in general the figures in Table 2 show a highly varied set of change patterns, only in a few instances is there any indication of the reform era producing new trends.

\section{Table 3 about here}

Finally, in Table 3 I present a variety of measures dealing with how the wedding was celebrated. For the most part these figures are strikingly different from those in the previous two tables, and we see here dramatic evidence of new trends in the reform era. The primary pattern in this table is not entirely a surprise, since the Chinese press has been filled with criticism of "excessive" wedding celebrations. In general, marriages have been celebrated more elaborately and expensively in the post-Mao era than in earlier periods. In the reform era marriage cohort (column 5) we can see that wedding celebrations and wedding banquets were more often held than for previous cohorts, that banquets more often took place in restaurants (the primary subcategory within "other" in \#5), that gifts of various kinds increased in frequency and expense, and that the total expenditure on weddings also rose. ${ }^{30}$ Several features of this main trend should be noted, however. First, it would appear that the era of the most frugal and ritually simple weddings was not, in fact, the Cultural Revolution, but the years from 1958 to $1965 .^{31}$

29. For discussions on this topic, see Li Xianfu, "Weihun tongjuzhe yongtandiao," (The aria of cohabiters), Wenhui yuekan, no. 12, 1987, pp. 2-9; Honig and Hershatter, op. cit., pp. 114-16.

30. The comparison with the Detroit figures on weddings and receptions is not too illuminating, but it does point to one contrast. In Chinese urban weddings the celebration itself is often followed by a meal for a smaller group of family members and close friends, while in American marriages the attendance at the reception often exceeds that at the wedding. The attendance and expenditure averages given in Table 3 (in \#2,4,10,12, and 14) are averages for only those who reported having the activity or exchange in question. If I computed averages for all women in the sample the resulting means would, of course, be lower. Because of the small number of cases for which bride prices figures were given, the trends in expenditures on this item (see \#12) are not very reliable, especially for the pre-1957 period.

31. Another curious finding, not shown in Table 3 , is that an officially preferred form of "socialist" weddings designed to inhibit excessive expenditures, has never been widely followed and is even less so in recent times. This is the "collective wedding." in which large numbers of couples are married together in a joint ceremony. The proportion of weddings that took this form in the four PRC marriage cohorts were $9 \%, 5 \%, 0 \%$, and $2 \%$. In this case the apparently most doctrinaire socialist era, the Cultural Revolution, was least likely to follow the preferred form of wedding, perhaps because of the organizational chaos of that period. 


\section{Figure 3 about here}

I wondered, though, whether economic privation or political radicalism contributed more to wedding simplification, since both were present in abundance in the 1958-65 period. To answer this question I performed another more fine-grained analysis. I constructed a seven item mean scale of wedding elaborateness and expenditures from items $\# 1,2,3,4,13,14$, and $15 .{ }^{32}$ The three year moving average of this wedding elaborateness scale is graphed across various years of marriage in Figure 3. Again, there are several different things that can be learned from such a graph. The overall pattern is one already familiar from Table 3--a decline in wedding elaborateness and expenditures and then a subsequent revival to if anything higher levels than at any point earlier, producing the rough $U$ curve visible in Figure 3 . In this case, as earlier, changes were underway even prior to 1949. During the depression and the early years of World War II wedding expenditures declined, with a partial revival that peaked in 1946, during the brief interlude between anti-Japanese and civil wars. Then the simplification trend resumed and continued after 1949. In general weddings were held to a fairly constant and spartan level throughout the period from 1953 to 1970 . Within this period the most spartan levels reached, during the post-Great Leap famine and the early, radical years of the Cultural Revolution, seem quite similar. What explains the differences between the two eras that I found in Table 3 is that the recovery and increasing elaborateness of weddings after 1970 was sharper and more sustained than the earlier partial recovery in the years 1963-5.

This comparison does not settle the issue of the relative contributions of economic and political influences, but it does reveal clearly that the trend toward increasing expenditures on weddings preceded the death of Mao, even if it has continued and even accelerated in the reform era. So this latest trend cannot be explained simply in terms of new policies and influences of the reform era. Factors such as the return to some degree of political and economic normalcy after

32. The methods used to construct this scale were the same as those described earlier in regard to the freedom of mate choice scale. The average item-to-item correlation among these seven wedding items was $r=.32$. 
the most chaotic years of the Cultural Revolution, as well as heightened anxiety about attracting a desirable mate, produced by the program of sending youth to the countryside and urban unemployment, may have contributed to this revival. Families were more willing and able to celebrate weddings with some fanfare in the final years of Mao's life, even before the reformers mounted the stage and made conspicuous consumption fashionable.

Returning to my examination of Table 3 , it is also interesting to note that of the various kinds of gift presentations that may occur in a wedding, the dowry appears to be most common and most expensive. This finding is somewhat of a surprise, since press critiques of wedding expenses mostly focus on exhorbitant demands made for gifts from the husband-to-be and his family to the bride-to-be. ${ }^{33}$ Our figures show that, although there are modest increases in the frequency and cost of such male gifts (see \#9 and \#10), these are dwarfed by the reported dowry transactions (see \#13 and \#14). One might speculate that in the current highly competitive urban marriage market, with particular anxiety expressed about the problem of "overage maidens" (daling guniang), family provision of a substantial dowry becomes an important method to attract a suitable groom, and high demands for gifts for the bride become a risky strategy. I also note that the figures in the table provide evidence for the point made earlier in Urban Life in Contemporary China: that in contemporary large cities, unlike in rural areas, "true" bride price payments from the groom's family to the bride's family are not generally involved.

Is the increased elaborateness of weddings expressed in traditional forms or in a Western mode? In most respects the figures in Table 3 point to some Westernization of weddings, rather than a revival of traditional customs. We do not see, for example, any taking of sedan chairs out of mothballs, while the use of bicycles and even automobiles to deliver the bride to the celebration is becoming more common (see \#6). In addition, wedding feasts in restaurants and honeymoon trips after the celebration are becoming increasingly common, just as happened earlier in places

33. In popular discussions of this topic one also hears the demands for gifts from the male to the bride stressed, and there are a variety of set phrases--"three rounds and one sound," "thirty legs," and so forth-which are used to denote the consumer durables and furniture that are expected. See also the discussion in Hong and Hershatter, op. cit., Chapter 4. 
like Hong Kong and Taipei. And most of the gifts exchanged are modern consumer durables and furniture, rather than items that would have gone into a traditional set of wedding gifts. ${ }^{34}$ And from anecdotal information not dealt with in our questionnaire we know of even more clear instances of Western influence on wedding customs. For example, in recent years it has become more and more common for urban couples to go to a photographer to have a formal wedding portrait taken, and for this portrait the bride wears a rented Western-style white wedding gown. Even though the gown is generally only worn in the photographer's studio, and not in the wedding celebrations themselves, still it will be this photo that will be hung on a wall in memory of the occasion.

Although much of the evidence from the Chengdu survey seems to point to Western or "modern" influences predominating in reform era weddings, still there are important exceptions. In particular, I note in \#8 that it has become less common in recent times, rather than more, for the bride and groom to start out married life in their own apartment. Neolocal residence was most common in the period from 1958 to 1965 , and since then starting out "in their own place" has decreased markedly, with both residence with the bride's parents and residence with the groom's becoming increasingly common (with the latter still more than twice as likely as the former). The most obvious explanation for this reversal of trends is the severe housing shortage in urban China generally, which even the extensive residential construction of the post-Mao era has not fully relieved. But whatever the cause, these results show that even though young people now pick their spouses in a non-traditional way, an increasing share of them have to start out married life living in a traditional family structure. ${ }^{35}$ And this trend is occurring despite signs in recent public opinion polls that there is increasing preference, by young people and even some old people, for nuclear family living. The familial interdependence expressed in these housing arrangements is also revealed in data about the pattern of payment for weddings (not displayed in

34. Our questionnaire asked about what items were included in the various kinds of wedding gifts, as well as about their value, although the information on specific items is not given here.

35. Of course, it could be noted that the $12 \%$ in the most recent cohort who married matrilocally are not being very traditional, since they are not moving in with the groom's parents. Still, they are establishing an extended family, rather than the sort of nuclear family that is the dominant form in competitive and individualistic modern societies. 
Table 3). As the expenditure on weddings has increased, the proportion of brides and grooms who pay for everything themselves has dropped from a high of $79 \%$ for Great Leap era marriages to only $28 \%$ among reform era couples. Increasingly, the resources of a diverse family network must be pooled to meet the expenditure required, and even grandparents and others are likely to chip in. ${ }^{36}$ So although I again stress that this interdependence upon an extended family does not indicate a return to a pattern of arranged marriages, still in certain respects the reform era trends in family life seem quite contrary to the move toward a more competitive and even individualistic society that China's reformers seem to be trying to foster.

What do the patterns in Table 3 tell us about the change mechanisms that are affecting wedding celebrations? In this instance we can see signs of all three mechanisms operating, and it is difficult to weigh their relative importance. It seems obvious that the relaxation of official pressure that fostered frugal weddings earlier has been important in permitting increasingly elaborate and public wedding celebrations to be held. One might even speculate that, despite official criticism of excessive expenditures on weddings, the authorities are not really too displeased, since the need to prepare for such costly affairs provides an important motivation for working harder, a motivation that was not required for a simple "tea and candy" wedding in the late Mao era. Envy of the incomes and consumption levels of others is, after all, seen by the reformers as a powerful incentive mechanism. In any case, official policy shifts that are the central dynamic of the directed change mechanism seem to have played an important role in the increasing scale of post-Mao urban marriages.

Structural changes appear to be at work as well. You have in the post-Mao era rising income levels and the kinds of increasing consumption aspirations that help to fuel competitive spending on weddings in more modern societies, ${ }^{37}$ but in addition you have a structural constraint

\footnotetext{
36. I have not included figures in Table 3 on the gifts-usually in cash-that couples received from guests at their weddings, but these have also increased and help to meet the costs of an elaborate wedding. To be specific, $100 \%$ of the Great Leap era weddings involved receipt of less than $400 Y$ from guests, but this was the case for only $45 \%$ of reform era weddings.

37. It might be noted that in the Detroit survey results I found evidence of increasing scale and ritual elaborateness of weddings in recent years, in spite of such trends as rising premarital cohabitation. I assume that the main basis for this trend in the Detroit sample is the rise in living standards and the return to "normalcy" that followed the depression and World War II.
} 
provided by a cramped housing supply, which helps to sustain extended family cooperation in meeting the demands of getting married. Finally, I have also noted a variety of ritual signs that Western influence is increasingly affecting how Chengdu residents marry. In general, then, all three mechanisms seem to be working together to help produce the dramatic changes in wedding celebrations in the reform era.

\section{Conclusions}

In this preliminary examination of the marriage experiences of urban women in Chengdu I have uncovered a number of complexities, rather than one simple pattern. If I focus only on the question of the social consequences of the post-Mao reforms, then my primary conclusion is that most aspects of marriage customs have not changed that much in the reform era. ${ }^{38}$ In many areas, particularly those related to freedom of mate choice, the reform era displays basic continuity with earlier periods, and some of the changes visible in the reform era, such as the increase in brides who married from intact families and a rising proportion of brides already in the work force, also are simple extensions of earlier patterns. Only in the realm of wedding celebrations do I see clear evidence that things have changed dramatically, and even in this realm changes were already underway in the late-Mao era. The reform era has made it possible and perhaps even necessary to engage in an elaborate and expensive set of wedding customs, and some contemporary weddings take a partially Westernized form that would have been criticized in earlier eras. But other aspects of the process of getting married have not changed nearly as much, and in some realms, such as the pattern of residence after marriage, there are even signs of reversion to more traditional Chinese patterns. Although to some extent I have utilized all three change mechanisms in explaining the specifics of the Chengdu findings, still on balance I would argue that the social structural change mechanism emerges as most important overall. In urban Chengdu the reforms have produced rising incomes, approval of competitive consumption,

38. One aspect of mate choice on which we have data in our Chengdu survey has not been dealt with here--the pattern of assortative mating, or of who marries whom. The complexities of examining status matching at marriage in terms of family background, education, party membership, and other factors, and how the degree of that matching may have changed over time will be dealt with in a subsequent work. 
and access to Western symbols to use in this competition, but the underlying structure of opportunities and controls within which urbanites operate has not changed all that much. Only if more substantial changes in this urban organizational structure occur can we expect to see sharp changes in other aspects of marriage customs such as we have seen in wedding celebrations. ${ }^{39}$

These observations lead to some final ruminations about the impact of socialist structural changes on family life. Earlier I noted that modernization/convergence theorists such as William Goode argue that the direction of family change in societies such as China is predictable--it is toward patterns that are increasingly similar to the "conjugal" family life that is found in contemporary Western societies. However, I also suggested that socialist transformation could hasten this process by accelerating the shift away from familial control over resources and opportunities. After reflecting on the figures presented in this paper, and particularly on those relating to freedom of mate choice, I feel I must qualify that argument. It would appear that in certain respects socialism does hasten the early stages of the family change process, but then the new institutional structures take hold and keep the process from going much further. In other words, the consolidated state socialist system may lead to "stalled convergence" in areas such as freedom of mate choice.

Major changes in the structure of that system could, as I have just noted, lead to a new acceleration in the family change process. However, the urban reforms to date do not entail such major structural changes, but instead are producing a more incremental modernization process that is comparable in some ways to what has occurred in capitalist societies. If this observation is correct, it means that the reforms could foster shifts toward the emergence of a true dating culture, increased levels of premarital sexual activity, and so forth. But such changes would only emerge gradually, as educational levels increased; jobs, housing, and other resources became increasingly available through market channels; and other forms of modernization gradually

39. For example. I would expect that if in the future market reforms progress much further than they have to date in urban China, reducing the dependence of young people upon both families and various bureaucratic gatekeepers, then more of a dating culture should develop, accompanied by increases in such things as having had more than one marital prospect. having experienced premarital sex, and living neolocally after marriage. 
evolved. This means that I should not be surprised that I can only see faint glimmerings of such changes in the Chengdu data. It is simply too early. After becoming accustomed to the sharp social changes which seemed to follow in the wake of Party pronouncements and campaigns in the Mao era, China analysts may have to get used to the idea that Chinese family life will evolve in slower and less dramatic ways. 
Table 1:Changes in Aspects of Freedom of Mate Choice in Chengdu

\begin{tabular}{rrrrrrr}
\multicolumn{8}{c}{ Year First Married } \\
$\mathrm{N}$ & $1933-48$ & $49-57$ & $58-65$ & $66-76$ & $77-87$ Detroit \\
\hline & 71 & 107 & 82 & 116 & 210 & 459
\end{tabular}

1.Trad. Arranged Mar

a.Arranged(\%)

b.Intermediate

c.Individual choice

69

22

1

0

$\begin{array}{ll}68 & 27 \\ 15 & 33 \\ 17 & 40\end{array}$

0
45
55

1
40
59

$\begin{array}{rr}2 & \text { n.a. } \\ 41 & \text { n.a. } \\ 57 & \text { n.a. }\end{array}$

3.Dominant Role in Mate Choice:

\begin{tabular}{llllrrr} 
a.Parents $(\%)$ & 56 & 30 & 7 & 8 & 5 & n.a. \\
b.Mixed & 15 & 11 & 6 & 3 & 6 & n.a. \\
c.Respondent & 28 & 59 & 87 & 89 & 89 & n.a. \\
\hline & 91 & 76 & 54 & 59 & 60 & 44 \\
\hline
\end{tabular}

4.Introduced to Husband $(\%)$

38

a. Own generation $(\%)$

b.Other

c.Parents' generation

8

43

17

40

75
7
18

75

6

19

$\begin{array}{rr}74 & 84 \\ 9 & 9 \\ 17 & 7\end{array}$

6.Dated Husband Prior to Marriage?

$\begin{array}{lrrrrrr}\text { a.Often(\%) } & 12 & 17 & 24 & 40 & 48 & \text { n.a. } \\ \text { b.Sometimes } & 6 & 18 & 27 & 13 & 21 & \text { n.a. } \\ \text { c. Rarely } & 23 & 22 & 30 & 31 & 24 & \text { n.a. } \\ \text { d.Never } & 59 & 44 & 18 & 16 & 7 & \text { n.a. }\end{array}$

7.Number of Romances:

\begin{tabular}{lrrrrrr} 
a.None $(\%)$ & 73 & 29 & 9 & 5 & 5 & 0 \\
b.One & 24 & 63 & 74 & 66 & 67 & 34 \\
c.More than one & 3 & 8 & 18 & 29 & 28 & 66 \\
\hline
\end{tabular}

\begin{tabular}{|c|c|c|c|c|c|c|}
\hline 8.Had Other Marital Prospects(\%) & 4 & 5 & 2 & 6 & 9 & 45 \\
\hline
\end{tabular}

9. How Much in Love When Married?

$\begin{array}{lrrrrrr}\text { a.Completely(\%) } & & & & & 47 \\ \text { b. } & 17 & 38 & 63 & 61 & 67 & 22 \\ \text { c. } & 26 & 29 & 22 & 26 & 19 & 14 \\ \text { d. } & 35 & 20 & 9 & 11 & 10 & 8 \\ \text { e.Not at all } & 9 & 4 & 4 & 1 & 3 & 4 \\ & 13 & 9 & 2 & 1 & 0 & 2\end{array}$

10.Doubts Before Wedding:

$\begin{array}{lrrrrrr}\text { a.Major doubts }(\%) & 1 & 3 & 2 & 0 & 4 & 11 \\ \text { b.Some doubts } & 4 & 10 & 12 & 14 & 17 & 24 \\ \text { c.No doubts } & 94 & 87 & 85 & 86 & 79 & 65\end{array}$

n.a. = not available 
Table 2:Changes in the Circumstances of Marriages in Chengdu

\begin{tabular}{crrrrrr}
\multicolumn{8}{c}{ Year First Married } \\
$\mathrm{N}$ & $1933-48$ & $49-57$ & $58-65$ & $66-76$ & $77-87$ Detroit \\
& 71 & 107 & 82 & 116 & 210 & 459
\end{tabular}

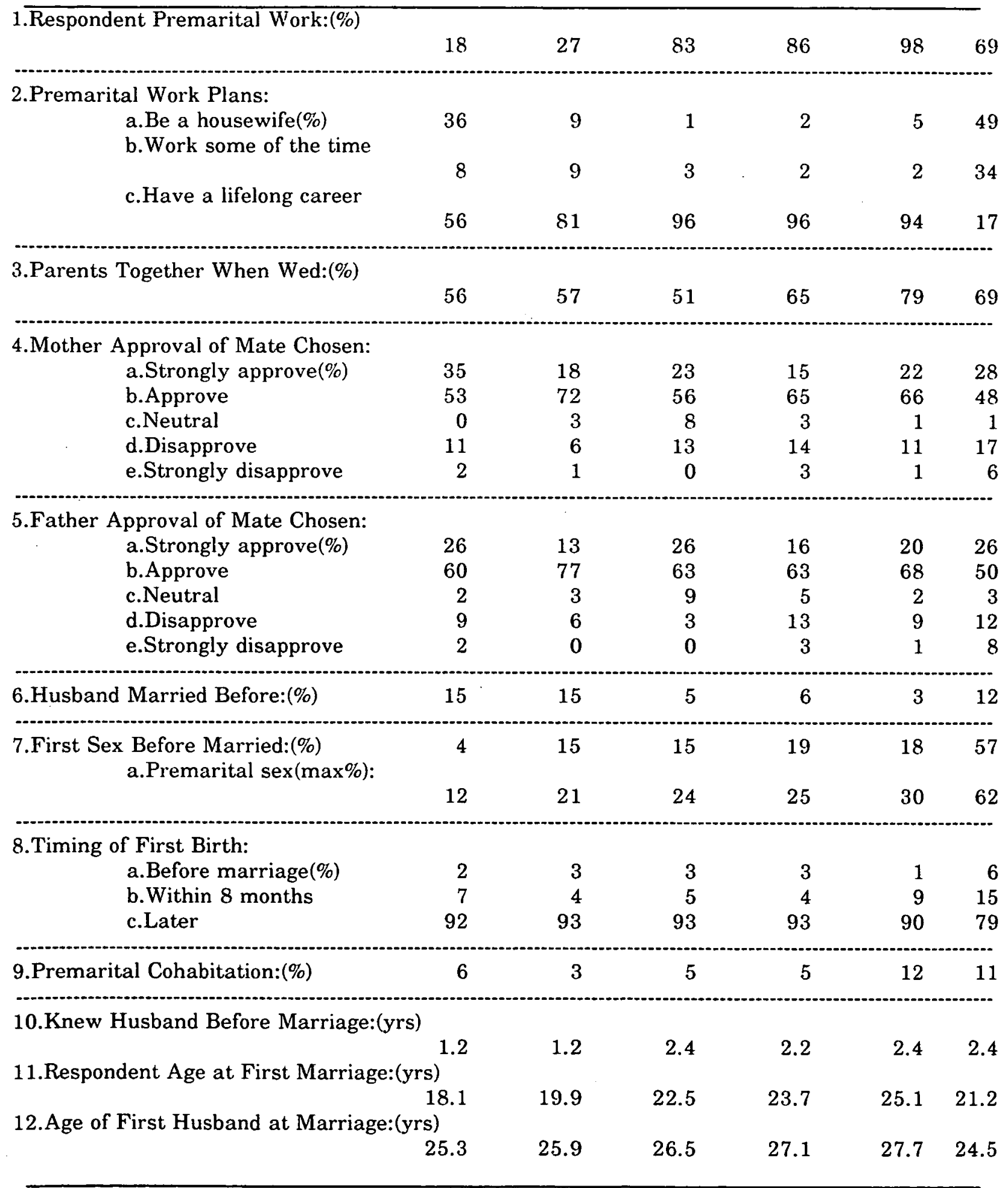


Table 3:Changes in Wedding Behavior in Chengdu

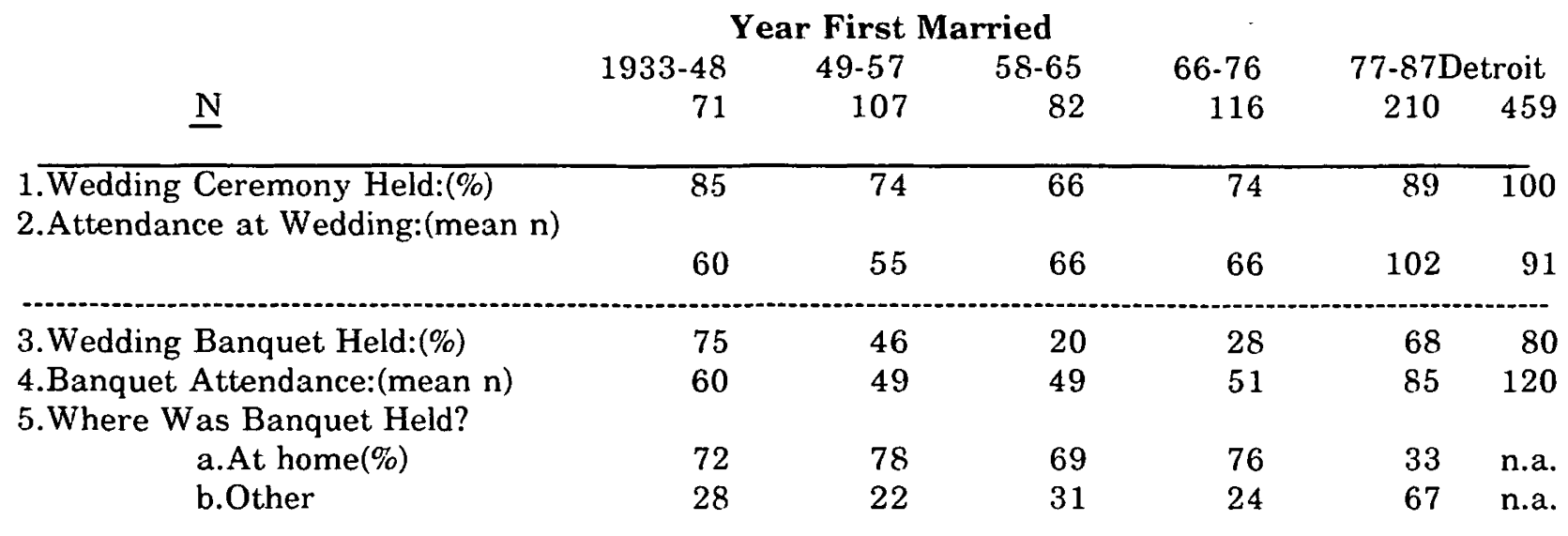

6.How Respondent Was Delivered to Wedding:

\begin{tabular}{lrrrrrr} 
a.Sedan chair(\%) & 55 & 22 & 0 & 0 & 0 & n.a. \\
b.Bicycle & 1 & 1 & 1 & 11 & 20 & n.a. \\
c.Automobile & 8 & 0 & 0 & 1 & 9 & n.a. \\
d.On foot & 24 & 50 & 67 & 71 & 50 & n.a. \\
e.Other & 11 & 27 & 32 & 17 & 21 & n.a. \\
\hline oon Trip Taken:(\%) & 1 & 3 & 2 & 14 & 21 & 54
\end{tabular}

8.Postmarital Residence:

a. With bride's family(\%)

$\begin{array}{lrrrrrr} & 10 & 7 & 4 & 7 & 12 & 9 \\ \text { b.With groom's family } & 45 & 25 & 13 & 16 & 28 & 10 \\ \text { c.In own place } & 39 & 64 & 71 & 68 & 51 & 70 \\ \text { d.Other } & 6 & 4 & 12 & 9 & 9 & 11\end{array}$

9.Gifts from Husband to Bride?(\%)

10.Value of Mean Gifts to Bride:(Y)

$\begin{array}{llllll}34 & 18 & 21 & 22 & 31 & \text { n.a. }\end{array}$

$\begin{array}{llllll}198.6 & 204.9 & 52.4 & 105.8 & 200.2 & \text { n.a. }\end{array}$

\begin{tabular}{lrrrrrr}
\hline 11.Bride Price Given:(\%) & 18 & 9 & 5 & 6 & 9 & n.a. \\
12.Value of Mean Bride Price: $(\mathrm{Y})$ & 35.9 & 158.9 & 23.3 & 49.7 & 61.9 & n.a. \\
\hline 13.Dowry Given to Bride:(\%) & 56 & 36 & 26 & 32 & 71 & n.a. \\
14.Value of Mean Dowry:(Y) & 228.7 & 167.3 & 139.2 & 128.1 & 343.4 & n.a.
\end{tabular}

15. Total Spent on the Wedding:

$\begin{array}{lrrrrrr}\text { a.Under 500 yuan }(\%) & 82 & 89 & 94 & 80 & 15 & \text { n.a. } \\ \text { b.500-999yuan } & 10 & 8 & 6 & 13 & 32 & \text { n.a. } \\ \text { c. } 1000+\text { yuan } & 7 & 3 & 0 & 7 & 53 & \text { n.a. }\end{array}$

n.a.= not available 


\section{Figure 1: Freedom of Mate Choice Moving Average}

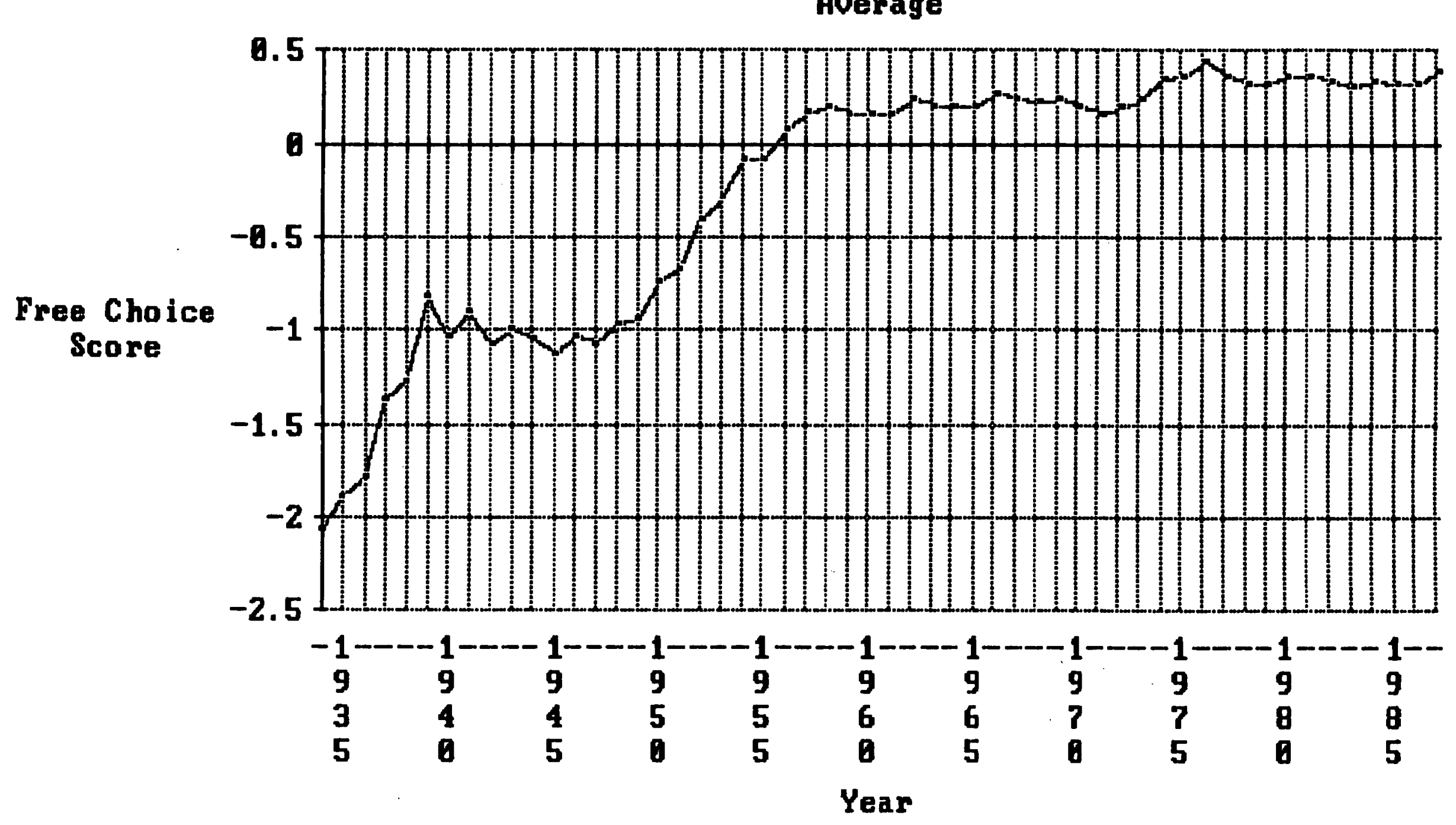


Figure 2: Bride Age at Marriage Moving Average

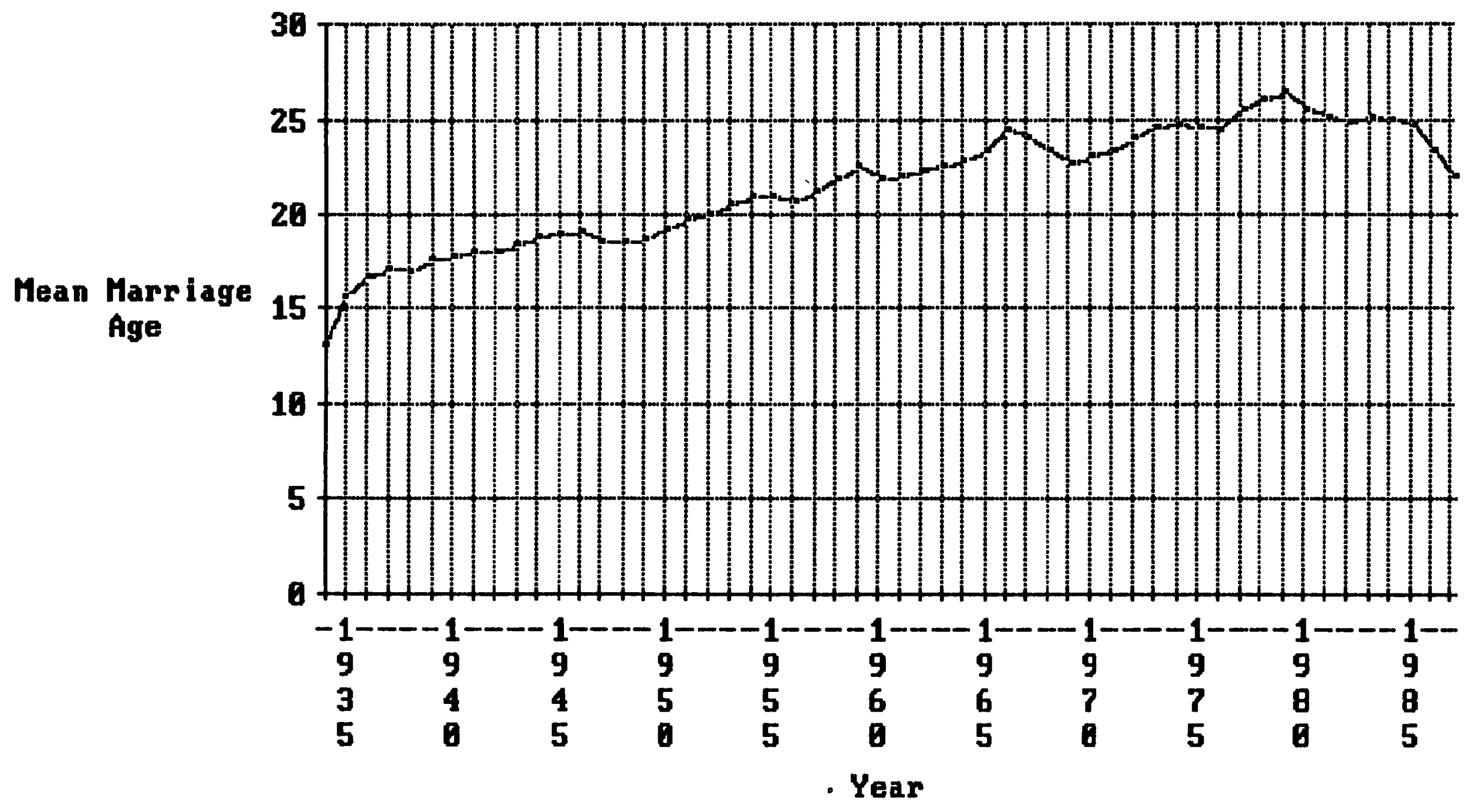




\section{CENTER FOR RESEARCH ON SOCIAL ORGANIZATION WORKING PAPER SERIES}

CRSO Working Papers report current research and reflection by affiliates of the Center. Working papers which are still in print are available for a fee of $\$ 2.00$ for any paper under 100 pages and $\$ 4.00$ for papers over 100 pages. The Center will photocopy out-of-print working papers at cost ( $f$ ive cents per page). To request copies of working papers, or for further information about the Center, write us at 4501 LS\&A Building, Ann Arbor, Michigan, 48109, or call (313)764-7487.

348 "Institutionalizing Conflict Management Alternatives," by Nancy Manring, September 1987,23 pages. Also POMA Working Paper \#7.

349 "Feminist Social Movement Organizations: The Construction of an Ideal Type," by Cheryl A. Hyde, September 1987, 25 pages.

350 "In Search of the Bourgeois Revolution: The Particularities of German History," by Geoff Eley, September 1987, 61 pages. Also CSST Working Paper \#4.

351 "Leading Self-Help Groups: Report on Workshop for Leaders of Childhood Cancer Support Group," by Toby Ayers and Mark Chesler, December 1987, 43 pages.

352 "Action Research in the Voluntary Sector: A Case Study of Scholar-Activist Roles in Self-Help Groups," by Mark A. Chesler, October 1987, 25 pages. Also PCMA Working Paper \#8.

353 "Multiple Levels of Conflict in Everyday Life: A Conference Sumary," by PCMA Staff, May 1987, 44 pages. Also POMA Working Paper \#9.

354 "Integrative Analytic Assessment: A Hybrid Method for Facilitating Negotiation," by Kan Chen and Steve Underwood, March 1988, 33 pages. Also PCMA Working Paper \#10.

355 "The Burdens of Urban History: The Theory of the State in Recent American Social History," by Terrence J. McDonald, July 1988, 42 pages. Also CSST Working Paper \#5.

356 "Multicultural Organization Development," by Bailey Jackson and Evangelina Holvino, July 1988, 22 pages. Also PCMA Working Paper \#11.

357 "History, Sociology, and Theories of Organization," by Mayer N. Zald, July 1988,33 pages. Also CSST Working Paper \#6.

358 "Have Social Historians Lost the Civil War? Some Preliminary Demographic Speculations," by Maris A. Vinovskis, July 1988, 46 pages. Also CSST Working Paper \#7.

359 "Innovative Participation in Neighborhood Service Organizations," by Barry Checkoway, August 1988, 32 pages. Also PCMA Working Paper \#12.

360 "Facing the Challenge of Diversity and Multiculturalism," by Judith H. Katz, Ed.D., August 1988, 55 pages. Also PCMA Working Paper \#13.

361 "Changes in Mate Choice in Chengdu," by Martin King Whyte, September 1988, 32 pages. 
. 